\title{
Nutritional status among pregnant women of Aligarh district and its association with birth weight
}

\author{
Khushboo Juneja $^{1 *}$, Najam Khalique ${ }^{2}$, M. Athar Ansari ${ }^{2}$, Anees Ahmad ${ }^{2}$, \\ Mohd Haroon Khan', Shahin ${ }^{1}$
}

\begin{abstract}
${ }^{1}$ Department of Community Medicine, SHKM Govt Medical College Nalhar (Mewat) Haryana India
${ }^{2}$ Department of Community Medicine, Jawaharlal Nehru Medical College, Aligarh Muslim University (AMU), Aligarh (U.P) India
\end{abstract}

Received: 01 January 2016

Accepted: 06 February 2016

\section{*Correspondence:}

Dr. Khushboo Juneja,

E-mail: khushboojuneja22@gmail.com

Copyright: (C) the author(s), publisher and licensee Medip Academy. This is an open-access article distributed under the terms of the Creative Commons Attribution Non-Commercial License, which permits unrestricted non-commercial use, distribution, and reproduction in any medium, provided the original work is properly cited.

\section{ABSTRACT}

Background: Low birth weight is a prospective marker of future growth and development and a retrospective marker of mothers nutritional and health status.

Methods: A community based prospective study conducted in field practice areas of Urban and Rural Health Training Center Department of Community Medicine, JNMCH, AMU, Aligarh. Participants were registered pregnant women who were in their first trimester and whose expected date of delivery lies within our study period. Study period was of one year. Data was analyzed using SPSS version 20. Percentages and chi square test used.

Results: Prevalence of LBW was found to be $40 \%$. Occurrence of LBW babies decreased as the nutritional intake of mothers in the form of kilocalories consumed per day increased. The association between dietary calorie intake and birth weight was found to be statistically highly significant.

Conclusions: Nutritional status of mother has to be improved not only during pregnancy, but also in her early childhood by undertaking food supplementation programs implemented through National Health Programs that improve the weight gain during delivery and result in improved fetal outcome.

Keywords: Nutritional status, Birth weight, Pregnancy

\section{INTRODUCTION}

Being undernourished in the womb increases the risk of death in the early months and years of a child's life. Those who survive tend to have impaired immune function and increased risk of disease; they are likely to remain undernourished, with reduced muscle strength, cognitive abilities and intelligence quotient throughout their lives. As adults, they suffer a higher incidence of diabetes and heart disease.

In developing country like ours, the nutritional status of women in reproductive age group is far from satisfactory.
The fertility rates are high and their diets are deficient in calories and many other essential nutrients from early childhood to adulthood. This long term chronic nutritional deprivation results in poor body size of mother. ${ }^{2}$ Pregnancy in such chronically undernourished mothers with perpetual semi-starvation throughout the gestation often results in delivery of low birth weight (LBW) babies, especially the growth retarded one.

\section{METHODS}

The present community based prospective study was conducted in the field practice areas of the Urban and Rural Health Training Centers, Department of 
Community Medicine, Jawaharlal Nehru Medical College, Aligarh Muslim University, Aligarh, Uttar Pradesh. The study subjects included in the study were residents of four registered areas of the urban health training center and seven registered villages of rural health training center. Study design was approved by Institutional Ethical Committee. A census of current pregnant women in their first trimester was prepared with the help of ASHA and medico social worker of our study area. Subsequent pregnancies were identified for next three months by periodic visits. These registered pregnant women who were in their first trimester and whose Expected Date of Delivery lie within our study period of one year were considered for study. Three home visits were made (two in antenatal period, one in post natal period).

I visit (as soon as she gets enrolled): Data on sociodemographic factors was collected. Obstetric history was taken. Dietary history was taken. A complete per abdomen examination, clinical profile along with anthropometric measurements and blood pressure was undertaken.

II visit (between 32-36 weeks) of gestation: Information regarding any medical illness during course of pregnancy. Data on no of tetvac injections and iron-folic acid tablets consumed during pregnancy was recorded. Weight gain, fundal height, abdominal girth and Blood Pressure was recorded.

III visit (after delivery of newborn): Questions regarding outcome of delivery and complications during delivery were asked. Sex of the newborn was noted. Examination of both mother and newborn was done to rule out any complications.

Weight of the baby was recorded (Institutional deliveryfrom record, home delivery-within 48 hrs of birth). Data was analyzed using SPSS version 20. Frequency, means, standard deviation was calculated. Chi square test and Fisher's exact test was applied wherever applicable. The value of $\mathrm{p}<0.05$ was considered as significant and $\mathrm{p}<0.001$ was considered as highly significant for this study.

\section{RESULTS}

Out of 185 study subjects in their first trimester who planned to deliver in our study areas, 20 (10.8\%) subjects had to be excluded as $15(8.1 \%)$ had abortion, and 5 $(2.7 \%)$ were lost to follow up. Hence study sample of 165 were followed up with three home visits. Out of these 5 $(3.0 \%)$ females were excluded as $2(1.2 \%)$ had twin delivery and had $3(1.8 \%)$ still births. Hence statistical analysis was done of 160 subjects. More than half (55\%) of respondents were from rural areas and $45 \%$ from urban areas. majority of females were of low (37.5\%) and medium (48.1\%) SLI. Out of total 160 live newborns, 64 were low birth weight babies. Thus the prevalence of
LBW was found to be $40 \%$. In rural areas prevalence was more of LBW babies (54.7\%) as compared to urban areas (45.3\%). The mean birth weight of all the 160 newborns was $2.58 \mathrm{~kg}$ (with $\mathrm{SD} \pm 0.55 \mathrm{~kg}$ ). As seen from Table-1, maximum newborns $(50.6 \%)$ lie within range of 2.5-3.4 $\mathrm{kg}$ and only $9.4 \%$ newborns were with birth weigh 3.5 $\mathrm{kg}$ or more. More numbers of males were born in rural areas $(56.8 \%)$ whereas in urban areas more females $(51.4$ $\%)$ were born. Most of females both in rural (76.2\%) and urban $(76.4 \%)$ areas delivered term babies (Table 1).

Table 1: Distribution of new-borns according to birth weight.

\begin{tabular}{|lll|}
\hline $\begin{array}{l}\text { Birth weight } \\
(\mathrm{Kg})\end{array}$ & No. of newborns & $\%$ \\
\hline$<1.5 \mathrm{~kg}$ & 4 & 2.5 \\
\hline $1.5-2.4$ & 60 & 37.5 \\
\hline $2.5-3.4$ & 81 & 50.6 \\
\hline$\geq 3.5$ & 15 & 9.4 \\
\hline Total & 160 & 100.0 \\
\hline
\end{tabular}

Figure 1 depicts distribution of study subjects according to Calorie intake during pregnancy. As seen from figure, majority of females of both rural $(56.8 \%)$ and urban (48.6\%) areas consumed 1500-2000 calories and very few pregnant women consumed more than 2500 calories both in rural and urban areas (Figure 1).

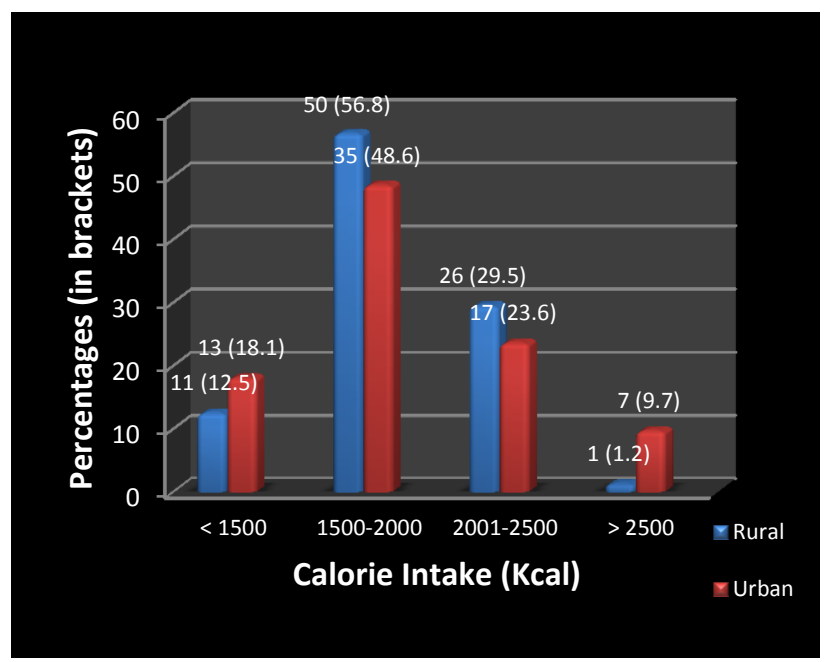

Figure 1: Distribution of study subjects according to calorie intake $(n=160)$.

Majority of patients were of low SLI and least number was of high SLI. Majority of the patients were consuming 1500-2000 calories in all the three SLI categories. Association between socio-economic status and calorie intake of pregnant female was insignificant (Table 2).

This finding may be due to the fact that as SLI increases, it is likely to reflect upon increased accessibility and affordability of health care and may also result in better nutritional status of mother. 
Table 3 depicts association of birth weight with calorie intake during pregnancy. As evident from table that occurrence of LBW babies decreased as the nutritional intake of mothers in the form of kilocalories consumed per day increased. The association between dietary calorie intake and birth weight was found to be statistically highly significant (Table 3).

Table 2: Standard of Living Index (SLI) and calorie intake of pregnant women $(\mathrm{n}=160)$.

\begin{tabular}{|c|c|c|c|c|c|c|}
\hline \multirow{4}{*}{ SLI } & \multicolumn{4}{|l|}{ Calories } & \multirow{3}{*}{\multicolumn{2}{|c|}{ Total }} \\
\hline & & & & & & \\
\hline & $<1500$ & $1500-2000$ & $2001-2500$ & $>2500$ & & \\
\hline & $\mathbf{N}(\%)$ & (N) $\%$ & $\mathbf{N}(\%)$ & (N) $\%$ & No & $\%$ \\
\hline Low & $14(23.3)$ & $33(55)$ & $10(16.7)$ & $3(5)$ & 60 & 37.5 \\
\hline Medium & $9(11.7)$ & $38(49.4)$ & $26(33.8)$ & $4(5.2)$ & 77 & 48.1 \\
\hline High & $1(4.3)$ & $14(60.9)$ & $7(30.4)$ & $1(4.3)$ & 23 & 14.4 \\
\hline Total & $24(15.0)$ & $85(53.1)$ & $43(26.9)$ & $8(5.0)$ & 160 & 100.0 \\
\hline
\end{tabular}

Table 3: Calorie intake during pregnancy and birth weight of baby $(n=160)$.

\begin{tabular}{|c|c|c|c|c|c|c|}
\hline \multirow{3}{*}{ Calories } & \multicolumn{4}{|c|}{ Birth weight of newborn } & \multirow{2}{*}{\multicolumn{2}{|c|}{ Total }} \\
\hline & \multicolumn{2}{|c|}{ Low birth weight } & \multicolumn{2}{|c|}{ Normal birth weight } & & \\
\hline & No. & $\%$ & No. & $\%$ & No. & $\%$ \\
\hline$<1500$ & 17 & 70.8 & 7 & 29.2 & 24 & 15.0 \\
\hline $1500-2000$ & 37 & 43.5 & 48 & 56.5 & 85 & 53.1 \\
\hline $2001-2500$ & 7 & 16.3 & 36 & 83.7 & 43 & 26.9 \\
\hline$>2500$ & 1 & 12.5 & 7 & 87.5 & 8 & 5.0 \\
\hline Total & 64 & 40.0 & 96 & 60.0 & 160 & 100.0 \\
\hline
\end{tabular}

\section{DISCUSSION}

LBW prevalence of our study is similar to that of Aligarh (37.4\%) according to Annual Health Survey conducted by Government of India (2012-13) 3 but higher than that as estimated by NFHS-3 $(22.5 \%){ }^{4}$

Gosavi et al, ${ }^{5}$ Badshah et al, ${ }^{6}$ Mumbare et al, ${ }^{7}$ Metgud et $\mathrm{al}^{8}$ found lower percentage of low birth weight than in present study. Solanki et $\mathrm{al}^{9}$ found similar percentage comparable with present study. However, Gogoi et $\mathrm{al}^{10}$ found higher percentage of low birth weight compared to present study.

Gawande et $\mathrm{al}^{11}$ in their cross-sectional study found that more than $50 \%$ of the babies were born into families belonging to the middle socio-economic strata (classes II $\&$ III), $23.3 \%$ and $12.2 \%$ belonged to the lower and upper classes respectively.

According to residential status, Kavita et $\mathrm{al}^{12}$ in their cross-sectional study found that urban mothers against $41.34 \%$ rural mothers; $41.33 \%$ rural against $24.67 \%$ urban; $17.33 \%$ rural against $6.00 \%$. urban and $7.33 \%$, urban against none of rural mothers consumed 2500 to
$3499 ; 2000$ to $2499 ; 1500$ to 1999 and 3500 to more than 4000 Kcal respectively.

Sachar et $\mathrm{al}^{13}$ in their study found that none of the women consumed more than $2500 \mathrm{kcal} /$ day, majority of women consumed less than 2000 calories.

This finding reflects the established fact that pregnancy in such chronically undernourished mothers with perpetual semi-starvation throughout the gestation often results in delivery of low birth weight (LBW) babies, especially the growth retarded one. Assessing the nutritional status of antenatal women and its correlation with fetal outcome (birth weight and perinatal mortality) may make us implement different programs to decrease perinatal mortality and improve fetal outcome. ${ }^{2}$

Some other researchers have also found the similar pattern in their study.

In a community based cohort study carried out by Choudhary et al, ${ }^{15} 91.7 \%$ newborns of women consuming between 1800 calories and 2000 calories were LBW. The proportion of LBW newborns came down with an increase in calorie consumption of mother. Among 
mothers consuming more than 2400 calories per day only $6.3 \%$ newborns were LBW.

Sachar et $\mathrm{al}^{13}$ in his longitudinal study in Ludhiana found that as the energy consumption increased, the frequency of low birth weight decreased and the difference was found to be statistically significant. The correlation coefficient ( $r$ ) of birth weight with energy consumed and deficit was observed to be 0.587 and -0.624 respectively $(\mathrm{p}<0.01)$.

Rao et al also carried out a longitudinal study among 141 pregnant women in the rural areas of district Ambala, Haryana. ${ }^{16}$ They have reported significantly higher prevalence $(82.7 \%)$ of LBW babies was observed in pregnant women with mean caloric intake of less than 1500 kcal, as compared to $12.8 \%$ among those consuming at least $1500 \mathrm{kcal} /$ day during the last trimester of pregnancy ( $\mathrm{p}<0.001)$.

\section{ACKNOWLEDGEMENTS}

I would like to express my profound gratitude to all the participants for their co-operation and for their immense faith they reposed in me.

\section{Funding: No funding sources}

Conflict of interest: None declared

Ethical approval: The study was approved by the Institutional Ethics Committee

\section{REFERENCES}

1. United Nations Children's Fund (UNICEF). Low birth weight: country, regional and global estimates. Switzerland: WHO Publications; 2004.

2. Lechtic A, Delgado H, Robert E, Lasky. Maternal nutrition and fetal growth in developing societies: socioeconomic factors. Am $\mathrm{J}$ dis Child. 1975;129:434-7.

3. Government of India. Annual Health Survey (AHS), 2012-13 fact sheet. New Delhi: Ministry of Home Affairs;2012-13.

4. National Family Health Survey-3(NFHS-3). International Institute for Population Sciences (IIPS) and Macro International. 2008. Available at http://www.hetv.org/india/ nfhs/nfhs3 /NFHS-3-
Chapter -09-Child-Health.pdf. Accessed on $28^{\text {th }}$ December, 2015.

5. Gosavi SV, Koparkar AR. Predictors of low birth weight: a retrospective study from rural India. Int J Contemp Pediatr. 2014;1:7-9.

6. Badshah S, Mason L, Mckelvie K, Payne R, Lisboa PJG. Risk factors for low birth weight in the public hospitals at Peshawar, NWFP, Pakistan. BMC Public Health. 2008;8:197.

7. Mumbare SS, Maindarkar G, Darade R, Yenge S, Tolani Mk, Patole K. Maternal risk factors associated with term low birth weight neonates: a matched-pair case control study. Indian Pediatr. 2012;49:25-8.

8. Metgud CS, Naik VA, Mallapur MD. Factors affecting birth weight of a newborn: a community based study in rural Karnataka, India. Plos One. 2012;7:1-4.

9. Solanki N, Kavishwar A, Chauhari V, Chhasatiya N. The effect of maternal anthropometric characteristics and social factors on birth weight of child in small town hospital of Gandevi block of Navsari district. Int J Med Sci Public Health. 2012;1:4-9.

10. Gogoi G, Ahmed FU. Effect of maternal nutritional status on the birth weight among women of tea tribe in Dibrugarh district. Indian $\mathbf{J}$ Community Med. 2007;32:100-2.

11. Gawande UH, Pimpalgaonkar MS, Bethariya SH. Bio-social determinants of birth weight in rural urban Nagpur. Indian J Community Med. 1994;16:64-7.

12. Kavita. Dietary intake of energy, protein and carbohydrate by expectant mothers in Varanasi district. Indian J Prev Soc Med. 2009;40:203-7.

13. Sachar RK, Kaur N, Soni RK, Dhot R, Singh H. Energy consumption during pregnancy \& its relationship to birth weight-a population based study from rural Punjab. Indian J Community Med. 2000;25:166-9.

14. Choudhary AK, Choudhary A, Tiwari SC, Dwivedi R. Factors associated with low birth weight among newborns in an urban slum community in Bhopal. Indian J Public Health. 2013;57:20-3.

15. Rao BT, Aggarwal AK, Kumar R. Dietary intake in third trimester of pregnancy and prevalence of LBW: a community-based study in a rural area of Haryana. Indian J Community Med. 2007;32:272-6.

Cite this article as: Juneja K, Khalique N, Ansari AM, Ahmad A, Khan MH, Shahin. Nutritional status among pregnant women of Aligarh district and its association with birth weight. Int J Reprod Contracept Obstet Gynecol 2016;5:696-9. 